\title{
Crohn's Disease with Oral Onset - A Case Report
}

\author{
Basirat $\mathbf{M}^{\mathbf{1}}$, Pakfetrat $\mathbf{A}^{\mathbf{2}}$, Kakaei $\mathbf{N}^{\mathbf{4}}$, Rohani $\mathbf{B}^{\mathbf{4}}$, Bashardoust $\mathrm{N}^{\mathbf{5}}$ \\ ${ }^{1}$ Assistant professor, Oral and Maxillofacial Medicine Dept,Dentistry Faculty, Guilan University of Medical Science, Rasht,Iran. \\ ${ }^{2}$ Professor, Oral Medicine Dept, Oral and Maxillofacial Disease Research Center, Mashhad University of Medical Sciences, Iran. \\ ${ }^{3}$ Dentist \\ ${ }^{4}$ Assistant Professor, Oral Medicine Dept, Faculty of Dentistry, AJA University of Medical Sciences, Tehran, Iran. \\ ${ }^{5}$ Assistant Professor, Oral and Maxillofacial pathology Dept, Dentistry faculty, Guilan University of Medical Sciences, Rasht, Iran.
}

\begin{tabular}{l}
\hline ARTICLE INFO \\
\hline Article Type \\
Case Report \\
Article History \\
Received: April 2016 \\
Accepted: July 2016 \\
ePublished: Oct 2016 \\
\hline
\end{tabular}

\section{Keywords:}

Crohn's disease,

Oral manifestation

\begin{abstract}
Background: Crohn's disease is an inflammatory bowel disease that can affect any part of the gastrointestinal (GI) tract including the mouth. Bowel symptoms are predominant. Oral involvement may precede the GI symptoms. This case report presents a patient affected by Crohn's disease with oral onset.

Case presentation: We present a 30-year-old pregnant woman complaining of chronic, multiple, yellow-white crusted ulcers predominantly involving the lips. In addition, there were small painless lesions on the palate, buccal and labial attached gingivae, buccal mucosa, alveolar mucosa and vestibule. The lesions were present since 3 months ago. The patient had not previously experienced any oral lesions or systemic diseases. The laboratory tests were normal. Laboratory investigation showed increase in neutrophil and eosinophil count. Incisional biopsy of the buccal mucosal lesions was performed. In histopathological examination, acanthotic and parakeratotic epithelium with intraepithelial clefts was observed. Inflammatory cells such as eosinophil and polymorphonuclear (PMN) leukocytes were profoundly present in the clefts and diffusely in the epithelium. Blood vessels, collagen fibers and in-depth muscle and fat tissues were also observed. Based on these characteristics, the diagnosis of pyostomatitis vegetans was made. Considering the biopsy results and the presence of GI symptoms such as abdominal pain and diarrhea after postpartum, Crohn's disease was suspected and therefore, the patient was referred to a gastroenterologist for definitive diagnosis and treatment. The patient showed the diagnostic signs of Crohn's disease. Conclusion: This report emphasizes the important role of oral lesions as the first sign in the diagnosis of systemic diseases.
\end{abstract}

\footnotetext{
Please cite this paper as:

Basirat M, Pakfetrat A, Kakaei N,Rohani B, Bashardoust N. Crohn's Disease with Oral Onset - A Case Report. J Res Dentomaxillofac Sci 2016;1(4):45-51
} 


\section{Introduction:}

The incidence of Inflammatory Bowel Diseases (IBD) has increased during the past century in the developed and developing countries. The increasing rates of Crohn's disease have also been reported in some studies, especially in Asian countries including Iran. ${ }^{(1,2)}$ During 1970 to 2012, twenty one documented articles were published regarding the epidemiology of IBD in Iran and 52 articles were published in Asia. ${ }^{(2)}$ IBD is a general term encompassing two chronic inflammatory tissue-destructive clinical entities in the GI tract: Crohn's disease (CD) and Ulcerative Colitis (UC). ${ }^{(3-5)}$

Crohn's disease has two peak incidences in the first and second decades of life inflicting 20 to 40 - and 55 to 65 -year-olds, respectively. ${ }^{(6,7)}$ Crohn's disease is a chronic condition that can involve the whole GI tract from the oral cavity to anus; however, the terminal portion of the ileum and the initial portion of the colon are usually involved during the disease. ${ }^{(3,5)}$ This disease is highly heterogeneous due to the broad range of clinical expressions. ${ }^{(5)}$ Bowel symptoms are predominant. The disease frequently presents with abdominal pain, fever, and clinical signs of bowel obstruction or diarrhea with passage of blood, mucus or both. ${ }^{(8)}$ Extra-intestinal complications may occur, including oral cavity involvement. ${ }^{(4,9)}$

A wide range of oral lesions has been clinically reported in Crohn's disease, including diffuse mucosal swelling, cobblestone appearance, localized mucogingivitis, deep linear ulceration, fibrous tissue tags, polyps or nodules, pyostomatitis vegetans and possible aphthous-like ulcers $^{(6)}$

In some articles, the oral lesions of Crohn's disease are divided into two categories: 1- Chronic deep linear ulcers with mucosal tag and rolled border in the buccal vestibule, and 2- Superficial oral ulcers such as aphthous ulcers. ${ }^{(10)}$ Here, we discuss a case of Crohn's disease with oral onset in a pregnant woman.

\section{Case presentation:}

A 30-year-old woman in the fifth month of pregnancy referred to the oral medicine department of Mashhad Dental Clinic. Extra-oral examination revealed chronic, multiple, yellowwhite, crusted ulcers and vegetation predominantly involving the lips. The lesions on the lips were asymptomatic, located on an erythematous base, and had the characteristic appearance of "snail-tracks". The lesions were present since 3 months previously. In addition, intra-oral examination showed small painless lesions on the palate, buccal and labial attached gingivae, alveolar mucosa and vestibule. (Figure1)

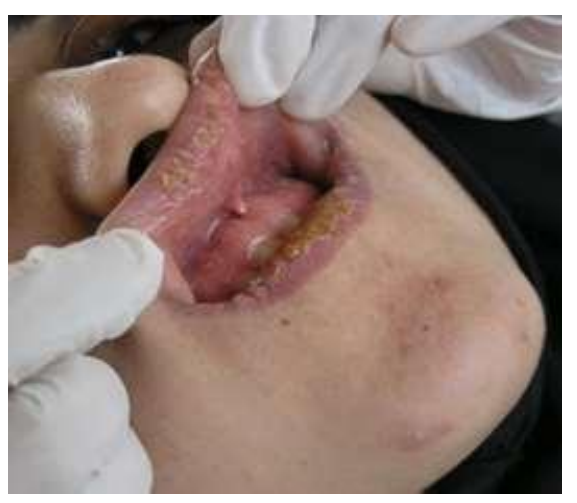

Figure 1- The ulcers on the upper and lower lips and gums with snail tract view.

However, the other signs and symptoms of Crohn's disease such as fatigue, prolonged diarrhea, cramps and abdominal pain, fever and weight loss were not present. ${ }^{(11)}$ The patient was also referred to a gynecologist for consultation. All the laboratory tests were normal including Complete Blood Count (CBC), blood chemistry including electrolytes, renal function tests, liver enzymes, and blood glucose, Erythrocyte Sedimentation Rate (ESR), C-reactive protein (CRP), vitamin B12 levels and serum iron.

The patient had not previously experienced any oral lesions or systemic diseases. Considering the chronic nature of the ulcers and vegetation, Crohn's disease and Pemphigus Vulgaris and Vegetans were considered in the differential diagnosis. Unfortunately, the biopsy was postponed up to two months after postpartum, as the patient did not refer for biopsy. During the next visit, the patient showed cobblestone appearance and more crusted ulcerations were observable on 
the upper and lower lips, gums and palate.

(Figure $2 \mathrm{a}, \mathrm{b}$ )

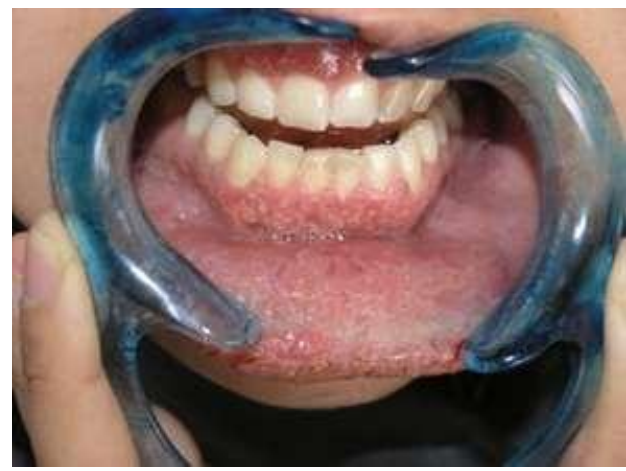

Figure 2a- The ulcers on the lower vestibule and gums with cobblestone appearance, two months after postpartum.

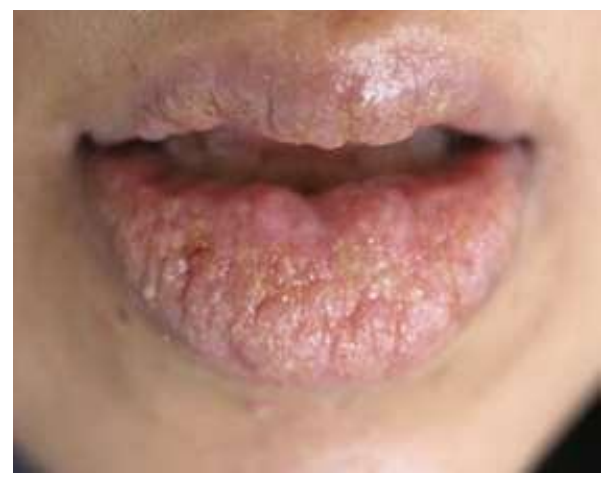

Figure 2b-The ulcers on the upper and lower lips with cobblestone appearance, two months after postpartum.

GI symptoms were also present. These symptoms indicated the progression of the disease. Laboratory investigations showed increase in neutrophil and eosinophil count. Incisional biopsy of buccal mucosal lesions was performed by an oral medicine specialist. In histopathological examination, acanthotic and parakeratotic epithelium with intraepithelial clefts was observed. Inflammatory cells such as eosinophil and polymorphonuclear (PMN) leukocytes were profoundly present in the clefts and diffusely in the epithelium. Blood vessels, collagen fibers and in-depth muscle and fat tissues were also observable. (Figure 3)

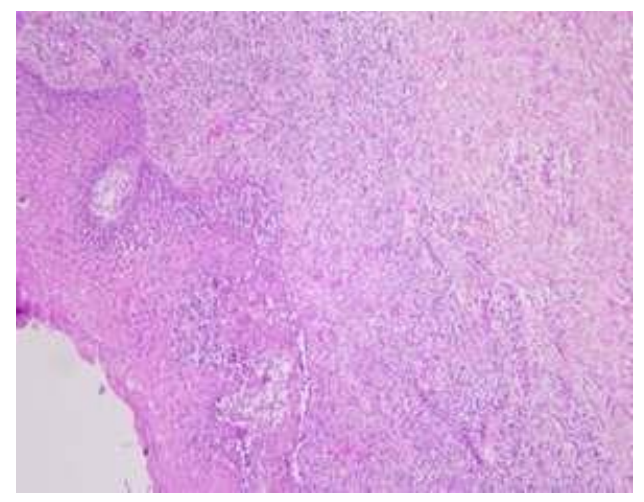

Figure 3- Low magnification is demonstrating the presence of acantotic and parakeratotic epithelium with intraepithelial clefts filled with a mixture of acute and chronic inflammatory cells with prominent eosinophils. H\&E staining, magnification $400 \times$.

Based on these characteristics, the diagnosis of pyostomatitis vegetans was made by an oral and maxillofacial pathologist.

Considering the biopsy results and the presence of GI symptoms such as cramps and abdominal pain and diarrhea after postpartum, Crohn's disease was suspected and therefore, the patient was referred to a gastroenterologist for definitive diagnosis and treatment. Endoscopy and colonoscopy were performed. After establishing the diagnosis of Crohn's disease, the patient was treated with $50 \mathrm{mg}$ daily dose of systemic corticosteroid and 100000 IU Nystatin drop taken 3 times a day for two weeks. After two weeks, the patient was instructed to taper down the prednisolone to 5-10 mg every four days, for six weeks. ${ }^{(12)}$ The oral lesions were controlled with simultaneous use of Chlorhexidine and Dexamethasone mouth washes $(0.5 \mathrm{mg} / 5 \mathrm{cc})$ three times a day for two months). The oral lesions were treated completely after two months. The patient was followed for 3 years and showed no recurrence of oral lesions.

\section{Discussion:}

Oral involvement is relatively common in Crohn's disease. ${ }^{(3)}$ The related oral mucosal lesions can appear before, at the same time or after 
the appearance of the intestinal lesions, and even without the presence of intestinal lesions. $(4,6)$ The disease with oral onset is rare, and only few cases of Crohn's disease with oral onset have been reported in PubMed from 2000 to 2015. (13-20)

Pyostomatitis vegetans is a highly characteristic sign of Crohn's disease. It is a rare pustular disorder of the oral mucosae. (21) Oral lesions may include multiple friable pustules with necrotic gray appearance on an erythematous base. They erode and form shadow snail tract ulcers which may affect all areas of the oral mucosae, although the most commonly affected sites are the labial and buccal mucosae, hard and soft palate, gingivae and sulci. ${ }^{(22)}$ The least affected sites are the tongue and floor of the mouth. ${ }^{(22,23)}$ Vegetation can be seen in areas of erythema, especially on the gingivae and palate. ${ }^{(23)}$ This disease may affect all age groups with 3:18 male to female ratio, and may be difficult to treat. ${ }^{(3)}$

The pathogenesis of pyostomatitis vegetans is poorly understood. ${ }^{(11)}$ It was believed that superimposition of noncaseating infections on the underlying disease or an underlying immune dysfunction may play a role in the pathogenesis, but currently, the main emphasis is on the immunological origin. $^{(23,11)} \mathrm{Also}$, it is believed that pyostomatitis vegetans may be accompanied by GI, skin and liver diseases. ${ }^{(24)}$

Pyostomatitis vegetans can be the first sign of Crohn's disease. These orofacial lesions may be misdiagnosed as common oral ulcers. The differential diagnosis of pyostomatitis vegetans includes: pemphigus vulgaris, pemphigus vegetans, bullous pemphigoid, and dermatitis herpetiformis.

GI symptoms and pustule formation are useful criteria to rule out these diseases. This disease should also be differentiated from herpetic lesions, erythema multiform, Behcet's syndrome, and bullous drug eruption. Chronic course, pustule formation and vegetation are the major criteria to rule out herpetic lesions and erythema multiform. The recurrent nature of the oral lesions without pustule formation and vegetation and also, positive pathergy test in Behcet's syndrome can help differentiate this disease from Crohn's disease. Systemic conditions and a history of drug use are the differentiating criteria of bullous drug eruption. ${ }^{(6,19,25,26)}$

Diagnosis of Crohn's disease is based on a number of findings including: description of the disease, appearance of the bowel wall, medical imaging, biopsy and histopathology. ${ }^{(8)}$ Peripheral eosinophilia is detectable in $90 \%$ of the reported cases. The histopathological appearance of pyostomatitis vegetans shows intra or sub epithelial clefts containing numerous eosinophils and neutrophils. ${ }^{(22,11)}$ Clinical, laboratory and histopathological findings of the present patient were consistent with Crohn's disease.

During pregnancy, white blood cell (WBC) and neutrophil count will increase and also, the cell-mediated immunity shifts from $\mathrm{T}$ helper 1 (Th1) to T helper2 (Th2) response. Estrogen and cortisol rates will also increase. ${ }^{(27)}$ In Crohn's disease, Th1 cells are predominant. ${ }^{(28)}$ These hematologic changes in Crohn's disease can make the $\mathrm{CBC}$ interpretation difficult during pregnancy.

Diffuse facial swelling and orofacial granulomatosis (OFG), which are the facial and oral manifestations of Crohn's disease may precede the GI manifestations. ${ }^{(19)}$ Oral localization of Crohn's disease is uncommon.

Sanderson et al explained that manifestation of GI abnormalities without GI symptoms is common in patients with OFG. ${ }^{(29)}$ In many patients, the intestinal symptoms may be mild and can go unrecognized; thus, most authors believe that the bowel must be thoroughly examined in the patients with suspected inflammatory bowel disease, even in the absence of specific symptoms. Usually, the clinical course of the oral lesions is parallel to the activity of inflammatory bowel disease; therefore, oral manifestations can be helpful markers in diagnosis and evaluation of IBD. ${ }^{(4)}$ The differential diagnosis of OFG and the diagnostic methods are listed in Table $1 .(9,14,18,30)$ Evidence is insufficient to support a general top-down treatment model for all patients with Crohn's disease. ${ }^{(8,30,31)}$ In most cases, short-term use of a fast acting agent (i.e. steroids or anti$\mathrm{TNF}$ ) has been recommended to achieve rapid 
Table 1- Differential diagnosis of orofacial granulomatosis (OFG)

\begin{tabular}{|c|c|c|}
\hline Disease & Oral manifestations & Diagnostic methods \\
\hline OFG & $\begin{array}{l}\text { Recurrent persistent swelling } \\
\text { deep linear ulcer } \\
\text { gingival enlargement } \\
\text { cervical lymphadenopathy } \\
\text { facial palsy } \\
\text { fissured tongue }\end{array}$ & $\begin{array}{l}\text { Normal hematologic test } \\
\text { Serologic test: increased } \mathrm{IgG}^{1}, \text { increased SACE }^{2} \text { test, } \\
\text { increased CRP } \\
\text { Normal chest } \mathrm{x} \text {-ray } \\
\text { Lack of digestive involvement } \\
\text { Noncaseating inflammation } \\
\text { Negative Microorganism staining } \\
\text { Variable reaction to patch test }\end{array}$ \\
\hline Crohn's disease & $\begin{array}{l}\text { Aphthous-like ulcer } \\
\text { Angular cheilitis } \\
\text { deep linear ulcer } \\
\text { diffuse mucosal swelling } \\
\text { localized mucogingivitis } \\
\text { fibrous tissue tags } \\
\text { cobblestone appearance } \\
\text { pustules }\end{array}$ & $\begin{array}{l}\text { Hematologic test: anemia } \\
\text { Serologic test: Decreased serum B12 and ferritin, } \\
\text { increased CRP, increased Th1cells }{ }^{5} \\
\text { Normal chest X-ray } \\
\text { digestive involvement } \\
\text { Variable reaction to patch test }\end{array}$ \\
\hline Sarcoidosis & $\begin{array}{l}\text { Single or multiple soft nodules in the } \\
\text { gingiva } \\
\text { Xerostomia } \\
\text { bone, salivary gland, lymph node, skin } \\
\text { and pulmonary involvement } \\
\text { facial palsy }\end{array}$ & $\begin{array}{l}\text { Hematologic test: eosinophilia } \\
\text { Serologic test: increased SACE }{ }^{2} \text { test, increased } \mathrm{CRP}^{3} \text { and } \\
\text { ESR }^{6} \text {, } \\
\text { Chest x-ray: bilateral hilar lymphadenopathy } \\
\text { kveim test } \\
\text { Lack of digestive involvement } \\
\text { Negative microbial culture } \\
\text { Normal reaction to patch test }\end{array}$ \\
\hline $\begin{array}{c}\text { Allergic } \\
\text { angioedema }\end{array}$ & $\begin{array}{l}\text { Non-pitting edema of the lips, tongue, } \\
\text { pharynx and face, } \\
\text { History of allergy } \\
\text { Perioral and periorbital involvement }\end{array}$ & $\begin{array}{l}\text { Normal hematologic test } \\
\text { Serologic tests: Increased } \operatorname{IgE} \\
\text { Normal chest } x \text {-ray } \\
\text { Lack of digestive involvement } \\
\text { Lack of granuloma formation }\end{array}$ \\
\hline Tuberculosis & $\begin{array}{l}\text { Cervical lymphadenitis } \\
\text { Localized swelling, } \\
\text { Chronic painless oral ulcers (tongue } \\
\text { and gingival ulcers) }\end{array}$ & $\begin{array}{l}\text { Caseating granuloma, } \\
\text { Chest x-ray: hilar adenopathy, fibrosis, cavitation, } \\
\text { caseating granuloma } \\
\text { Ziehl-Neelsen stain, } \mathrm{PAS}^{7} \text { test }\end{array}$ \\
\hline Leprosy & $\begin{array}{l}\text { Skin, nose and palate involvement, } \\
\text { facial palsy }\end{array}$ & $\begin{array}{l}\text { Granulomatous inflammation } \\
\text { Positive PAS }{ }^{7} \text { test }\end{array}$ \\
\hline $\begin{array}{l}\text { Cheilitis } \\
\text { glandularis }\end{array}$ & $\begin{array}{l}\text { Labial enlargement with ulcers, acute } \\
\text { and chronic inflammation (without } \\
\text { granulomas) within the minor salivary } \\
\text { glands of the lips }\end{array}$ & $\begin{array}{l}\text { Normal hematologic and serologic tests } \\
\text { Normal chest x-ray } \\
\text { Lack of digestive involvement }\end{array}$ \\
\hline $\begin{array}{l}\text { Foreign body } \\
\text { reactions }\end{array}$ & $\begin{array}{l}\text { Labial and mucosal chronic } \\
\text { enlargement }\end{array}$ & Noncaseating granuloma \\
\hline $\begin{array}{l}\text { Deep fungal } \\
\text { infection }\end{array}$ & $\begin{array}{l}\text { Painful gingival ulcer, cervical } \\
\text { lymphadenopathy, erythema nodosum }\end{array}$ & $\begin{array}{l}\text { Microorganism Culture } \\
\text { Titration of antibody } \\
\mathrm{PAS}^{7} \text { staining }\end{array}$ \\
\hline
\end{tabular}

symptoms relief and disease control.

1.IgG, immunoglobulin G; 2. SACE, serum angiotensin converting enzyme; 3. CRP, Creactive protein; 4. C1INH, C1 esterase inhibitor; 5. Th, T helper cells; 6. ESR, erythrocyte sedimentation rate; 7. PAS, Periodic acid-Schiff. 
This agent should be used in combination with Thiopurines for long-term maintenance. ${ }^{(8,31-33)}$

Surgical treatment is considered for severe cases. Merigo et al treated a case with orofacial granulomatosis by the use of low level laser. ${ }^{(10)}$ Young age, immediate need for corticosteroids, perianal disease, colonic resection, repeated small bowel resection, a stricturing phenotype, substantial weight loss, and specific endoscopic lesions might predict a disabling disease course. (14) Patients with Crohn's disease are at risk for early small bowel and colorectal cancer. ${ }^{(34)}$ Therefore, early diagnosis and treatment are very important. Management of the oral lesions is based on treatment of the underlying GI disease. Antiseptic mouthwashes and topical corticosteroids are helpful in treating the oral lesions. ${ }^{(25)}$

\section{Conclusions:}

The oral lesions especially pyostomatitis vegetans may precede the GI symptoms in Crohn's disease. Since these oral lesions are often misdiagnosed as simple oral ulcers, careful examination of the oral cavity may reveal the findings indicative of the underlying systemic condition and allows early diagnosis and treatment.

\section{Acknowledgements:}

The authors sincerely thank Dr. Shadi Saghafi for histopathology investigations.

\section{Conflicts of Interest:}

The authors of this manuscript certify that they have no conflicts of interest regarding this research.

\section{References:}

1.Vahedi H, Merat S, Momtahen S, Olfati G, Kazzazi A-S, Tabrizian T, et al. Epidemiologic characteristics of 500 patients with inflammatory bowel disease in Iran studied from 2004 through 2007. Arch Iran Med 2009;12(5):454-60.

2.Malekzadeh F, Alberti C, Nouraei M, Vahedi H, Zaccaria I, Meinzer U, et al. Crohn's disease and early exposure to domestic refrigeration. PLoS One 2009;4(1):e4288.

3.Galbraith SS, Drolet BA, Kugathasan S, Paller
AS, Esterly NB. Asymptomatic inflammatory bowel disease presenting with mucocutaneous findings. Pediatrics 2005;116(3):e439-e44.

4.Lourenço SV, Hussein TP, Bologna SB, Sipahi AM, Nico MM. Oral manifestations of inflammatory bowel disease: a review based on the observation of six cases. J Eur Acad Dermatol Venereol 2010;24(2):204-7.

5.Ruiz Serrato A, Marín García D, Guerrero León MA, Vallejo Herrera MJ, Villar Jiménez J, Cárdenas Lafuente F, et al. Palpebral ptosis, a rare ocular manifestation of Crohn's disease. Arch Soc Esp Oftalmol 2013;88(8):323-6.

6.Katz J, Shenkman A, Stavropoulos F, Melzer E. Oral signs and symptoms in relation to disease activity and site of involvement in patients with inflammatory bowel disease. Oral Dis 2003;9(1):34-40.

7.Benchimol EI, Fortinsky KJ, Gozdyra P, Van den Heuvel M, Van Limbergen J, Griffiths AM. Epidemiology of pediatric inflammatory bowel disease: a systematic review of international trends. Inflamm Bowel Dis 2011;17(1):423-39.

8.Baumgart DC, Sandborn WJ. Crohn's disease. Lancet 2012;380(9853):1590-605.

9.Chi AC, Neville BW, Krayer JW, Gonsalves WC. Oral manifestations of systemic disease. Am Fam Physician 2010;82(11):1381-8.

10.Merigo E, Fornaini C, Manfredi M, Meleti M, Alberici F, Corcione L, et al. Orofacial granulomatosis treated with low-level laser therapy: a case report. Oral Surg Oral Med Oral Pathol Oral Radiol 2012;113(6):e25-9.

11.Mays JW,Sarmadi M,Moutsopoulos NM. Oral manifestations of systemic autoimmune and inflammatory diseases: diagnosis and clinical management. J Evid Based Dent Pract 2012;12(3 Suppl):265-82.

12.Longui CA. Glucocorticoid therapy: minimizing side effects. J Pediatr (Rio J) 2007;83(5 Suppl):S163-77.

13. William T, Marsch WC, Schmidt F, Kreft B. Early oral presentation of Crohn's disease. J Dtsch Dermatol Ges 2007;5(8):678-9.

14.Dupuy A, Cosnes J, Revuz J, Delchier JC, Gendre JP, Cosnes A. Oral Crohn disease: clinical characteristics and long-term follow-up of 9 cases. Arch Dermatol 1999;135(4):439-42.

15.Mignogna MD, Fortuna G, Leuci S, Amato M. Oral Crohn's disease: a favorable clinical re- 
sponse with delayed-release triamcinolone acetonide intralesional injections. Am J Gastroenterol 2008;103(11):2954-5.

16.Zbar AP, Ben-Horin S, Beer-Gabel M, Eliakim R. Oral Crohn's disease: Is it a separable disease from orofacial granulomatosis? A review. J Crohns Colitis 2012;6(2):135-42.

17.Stavropoulos F, Katz J, Guelmann M, Bimstein E. Oral ulcerations as a sign of Crohn's disease in a pediatric patient: a case report. Pediatric dent 2004;26(4):355-8.

18.Girlich C, Bogenrieder T, Palitzsch KD, Schölmerich J, Lock G. Orofacial granulomatosis as initial manifestation of Crohn's disease: a report of two cases. Eur J Gastroenterol Hepatol 2002;14(8):873-6.

19.Mignogna MD, Fedele S, Lo Russo L, Lo Muzio L. Orofacial granulomatosis with gingival onset. J Clin Periodontol 2001;28(7):692-6.

20. Grave B, McCullough M, Wiesenfeld D. Orofacial granulomatosis-a 20-year review. Oral Dis 2009;15(1):46-51.

21.Chaudhry SI, Philpot NS, Odell EW, Challacombe SJ, Shirlaw PJ. Pyostomatitis vegetans associated with asymptomatic ulcerative colitisA case report. Oral Surg Oral Med Oral Pathol Oral Radiol Endod 1999;87(3):327-30.

22. Merkourea SS, Tosios KI, Merkoureas S, Sklavounou-Andrikopoulou A. Pyostomatitis vegetans leading to Crohn's disease diagnosis. Ann Gastroenterol 2013;26(2):187.

23.Brinkmeier T, Frosch PJ. Pyodermatitispyostomatitis vegetans: a clinical course of two decades with response to cyclosporine and low-dose prednisolone. Acta Derm Venereol 2001;81(2):134-6.

24.Anand P, Kunnumakkara AB, Newman RA, Aggarwal BB. Bioavailability of curcumin: problems and promises. Mol Pharm 2007;4(6):80718.

25.Bogenrieder T, Rogler G, Vogt T, Landthaler M, Stolz W. Orofacial granulomatosis as the initial presentation of Crohn's disease in an adolescent. Dermatology 2003;206(3):273-8.

26.Ciacci C, Bucci C, Zingone F, Iovino P, Amato M. Buccal localization of Crohn's disease with long-term infliximab therapy: a case report. J Med Case Rep 2014;8:397.

27. Chandra S, Tripathi AK, Mishra S, Amzarul M, Vaish AK. Physiological changes in hematological parameters during pregnancy. Indian $\mathbf{J}$
Hematol Blood Transfus 2012;28(3):144-6.

28.Maccioni F, Bruni A, Viscido A, Colaiacomo MC, Cocco A, Montesani C, et al. MR Imaging in Patients with Crohn Disease: Value of T2-versus T1-weighted Gadolinium-enhanced MR Sequences with Use of an Oral Superparamagnetic Contrast Agent. Radiology 2006;238(2):517-30.

29.Sanderson J, Nunes C, Escudier M, Barnard K, Shirlaw P, Odell E, et al. Oro

granulomatosis: Crohn's disease or a new inflammatory bowel disease? Inflamm Bowel Dis 2005;11(9):840-6.

30.Leao JC, Hodgson T, Scully C, Porter S. Review article: orofacial granulomatosis. Aliment Pharmacol Ther 2004;20(10):1019-27.

31.Baert F, Moortgat L, Van Assche G, Caenepeel $\mathrm{P}$, Vergauwe P, De Vos M, et al. Mucosal healing predicts sustained clinical remission in patients with early-stage Crohn's disease. Gastroenterology 2010;138(2):463-8.

32. Terdiman JP, Gruss CB, Heidelbaugh JJ, Sultan S, Falck-Ytter YT. American Gastroenterological Association institute guideline on the use of thiopurines, methotrexate, and anti-TNF- $\alpha$ biologic drugs for the induction and maintenance of remission in inflammatory Crohn's disease. Gastroenterology 2013;145(6):1459-63.

33.Bokhari SA1, Khan AA, Butt AK, Azhar M, Hanif M, Izhar M et, al. Non surgical periodontal therapy reduces coronary heart disease risk markers: a randomized controlled trial. J Clin Periodontol 2012;39(11):1065-74.

34.Canavan C, Abrams KR, Mayberry J. Meta analysis: colorectal and small bowel cancer risk in patients with Crohn's disease. Aliment Pharmacol Ther 2006;23(8):1097-104. 